\title{
Medium Voltage Power Supply with Enhanced Ignition Characteristics for Plasma Torches
}

\author{
Kyungsub Jung* and Yongsug $\operatorname{Suh}^{\dagger}$ \\ $\dagger *$ Dept. of Electrical Eng., Chonbuk National University, Jeonju, Korea
}

\begin{abstract}
This paper investigates a power supply of medium voltage with enhanced ignition characteristics for plasma torches. A series resonant half-bridge topology is presented as a suitable ignition circuitry. The ignition circuitry is integrated into the main power conversion system of a multi-phase staggered three-level dc-dc converter with a diode front-end rectifier. A plasma torch rated at $3 \mathrm{MW}, 2 \mathrm{kA}$ and having a physical size of $1 \mathrm{~m}$ is selected to be the high enthalpy source for a waste disposal system. The steady-state and transient operations of a plasma torch are simulated. The parameters of a Cassie-Mary arc model are calculated based on 3D magneto-hydrodynamic simulations. The circuit simulation waveform shows that the ripple of the arc current can be maintained within $\pm 10 \%$ of its rated value under the presence of a load disturbance. This power conversion configuration provides a high enough ignition voltage, around 5KA, during the ignition phase and high arc stability under the existence of arc disturbance noise resulting in a high-performance plasma torch system.
\end{abstract}

Key Words: Half-bridge resonant converter, Medium voltage, Plasma torch, Waste disposal system

\section{INTRODUCTION}

The reduction of greenhouse gas emissions has become a challenging problem in many industrial sectors. The municipal waste disposal industry and the coal-fired furnace metal industry have been regarded as two of the many possible industry sectors that can bring down the emission of greenhouse gas by employing an environmentaly-friendly power conversion system. High enthalpy plasma torches have been widely used for the incineration of waste materials to reduce organic toxins and to vitrify the solid materials through their volume reduction in a non-leachable compact state. The thermal plasma torch is a device believed to have the potential to reduce greenhouse gas emissions in the industry sectors that are currently based on coal-fired furnace technologies [1]-[4]. The plasma torch systems have an intrinsic electrical characteristic of negative dynamic resistance during steady-state operation [1]. Due to the dynamic characteristics of high enthalpy plasma flows and arc fluctuations, a plasma torch system generates an alternating disturbance input to the overall power conversion system [5], [6]. This alternating disturbance input together with the negative dynamic resistance characteristic occasionally leads to the extinguishment of a plasma arc unless properly stabilized by fast regulation of the arc current. In addition, during the arc ignition phase, the plasma torch requires a high ignition arc voltage and a quick limitation of the arc current once it is ignited. In a variety of application fields for plasma torch

\footnotetext{
Manuscript received Oct. 8, 2010; revised Apr. 8, 2011

Recommended for publication by Associate Editor Kyo-Beum Lee.

$\dagger$ Corresponding Author: ysuh@jbnu.ac.kr

Tel: +82-63-270-3381, Fax: +82-63-270-2394, Chonbuk Nat'l University

* Dept. of Electrical Eng., Chonbuk National University, Korea
}

systems, the starting and igniting of plasma torches usually employs a sophisticated operational control schemes in order to provide enough ignition voltage and to limit the arc current once ignited. These operational control schemes often make the start-up of plasma torch systems difficult and costly. The unstable electrical characteristics of plasma torches during the steady-state and the ignition phase pose challenging problems in the design and operation of reliable power supply systems for plasma torches [7], [8].

For several years, diode and thyristor rectifiers have been the dominant technology platform in large current rectifiers for the application of electrochemical, electro-winning, graphite resistive heating, dc arc furnaces, etc. [9]. Due to its several drawbacks such as slow line and load responses, low disturbance stiffness, and limited ignition capability, the application of thyristor rectifiers in plasma torch systems tends to cause operational problems, i.e. ignition failures and arc extinguishment during the steady-state condition.

In order to overcome these operational problems, thyristor rectifiers often necessitate auxiliary ignition circuitry and arc stabilizing equipment such as ballast inductors, variable resistors, or on-load tap changers (OLTC). In [10]-[15], chopper solutions employing IGBTs and IGCTs have been proposed for general purpose high current rectifiers including both metal and electro-chemical applications. Owing to their high switching frequency and wide voltage conversion ratio, chopper solutions generally outperform thyristor rectifiers in plasma torch applications. Some of its applications to plasma torches have been briefly listed in [15]. The necessary features required for the power supply in a plasma torch system have been investigated along with the physical characteristics of the 


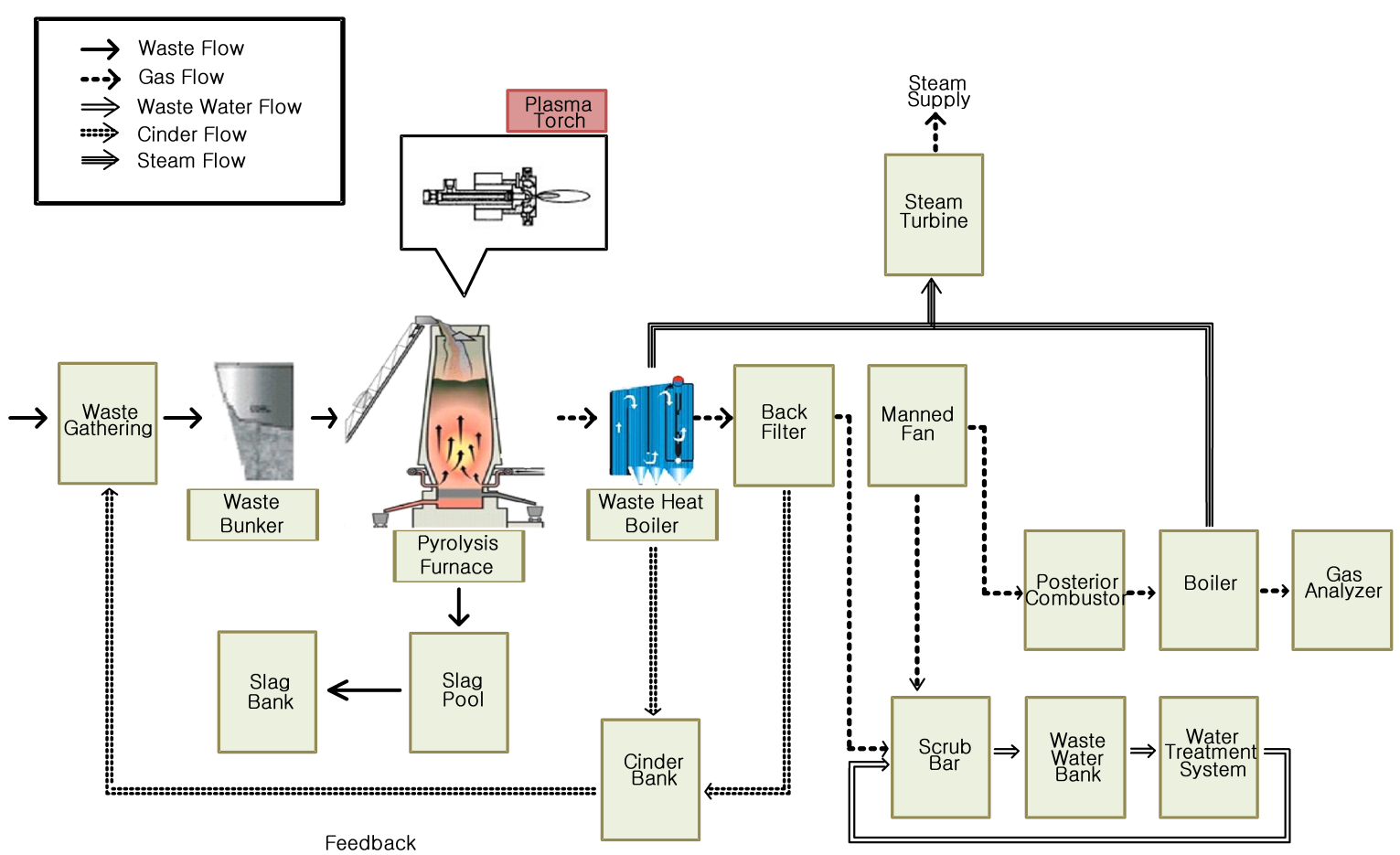

Fig. 1. Pyrolysis incinerator employing a plasma torch in waste disposal system [16].

plasma torch itself in [5], [6].

However, very little literature that deals with the design of power converters for plasma torch systems with respect to the dynamic arc and load characteristics during the ignition phase can be found. Considering the importance of an effective and simple start-up for plasma torches in industrial practice, the optimal design and operation of ignition circuitry for plasma torch systems have been paid little attention in the literature. This paper investigates a power conversion system of medium voltage for plasma torches under dynamic operating conditions during the arc ignition phase. The physical characteristics of plasma torches under dynamic operating conditions are modeled and simulated based on three-dimensional magneto-hydrodynamic computation. The results of this threedimensional simulation are used to formulate the CassieMayr equation for the plasma arc. A relevant circuit model of the plasma arc system is derived from the Cassie-Mayr equation. A series resonant half-bridge topology is presented as a suitable ignition circuitry in this paper. The ignition circuitry is integrated into the main power conversion system of a multi-phase staggered three-level dc-dc converter with a diode front-end rectifier. The proposed converter topology can generate a relatively high arc voltage due to the series connected voltage source structure. It can also provide high arc stability due to a relatively high effective carrier frequency. The arc model, based on the Cassie-Mayr equation, including proper physical constants for the ignition phase, is integrated into the circuit simulation of the proposed converter topology. The complete system simulation including a circuit model of a plasma torch confirms the operational characteristics of the proposed converter system.

\section{Medium Voltage Main Power Conversion SYSTEM FOR PLASMA TORCHES}

A waste disposal system employing a thermal plasma torch for pyrolysis incinerator is illustrated in Fig. 1 [16]. Among the various types of plasma torch systems, a medium-sized 3MW dc plasma torch with a hollow-electrode and a non-transferred arc is selected in this paper. A plasma torch requires a relatively high ignition voltage during the arc ignition phase when compared to the steady-state condition. In general, this high ignition voltage is provided by auxiliary ignition circuitry. Once the arc is established, the surging arc current should be limited to within a safe operating area of the converter system by a suitable circuit operation. A plasma torch, by itself, imposes a significant load disturbance of high frequency upon a power conversion system even during steady-state operation as described in previous sections. This may give a rise to a fluctuating load current and eventually lead to an extinction of the arc unless a proper control algorithm is employed.

Thyristor rectifiers have been widely used in many industrial applications that require a high dc current supply [9], [15]. A typical 12-pulse thyristor rectifier connected in parallel is shown in Fig. 2. It has been anticipated that this thyristor rectifier can also be applied to a plasma torch system [9]. The output voltage range of a thyristor rectifier is usually determined by a suitable range of the firing angle and the available on-load tap changer (OLTC) in the input transformer. The range of the firing angle depends on many system factors such as the specified power factor, the safe commutation range, the input/output harmonic requirements, etc. The availability of an on-load tap changer in the input transformer is also limited by system cost and durability. The voltage regulation speed, based on a mechanical tap changer, is not comparable 
to that of an electronic switch. In addition, the relatively short life cycle of an on-load tap changer is a serious drawback in industry. Therefore, the wide range of output voltage required for the power supply system of a plasma torch cannot be well satisfied by thyristor rectifiers. The line-commutated nature of a thyristor rectifier puts a limit on the output current regulation speed. When coupled with an on-load tap changer, the current regulation becomes even slower. Thus, two critical and necessary requirements for the power supply of a plasma torch, a wide range of output voltage including the ignition period and a fast current control feature, are not effectively achieved by thyristor rectifiers.

In applications where a fast control dynamic for the output current is required, such as in plasma torches and dc arc furnaces, a chopper rectifier like the one shown in Fig. 3 is often utilized [15]. The much faster system response of IGBTs reduces the short-circuit current excursions in dc arc furnace applications [10]. The power supply system shown in Fig. 3 consists of double-stage power converters. This configuration brings the benefits of a higher power factor and low harmonic generation on the ac main side. Depending on the load current demand and the basic configuration of a IGBT power cell, various types of connections on the input and output side of a IGBT power cell are possible [10], [11]. As the current and power rating of the load increases, the number of IGBT power cells connected in parallel also increases leading to a considerable rise in system cost including the output filter choke. The system design tends to choose a higher switching frequency and further multi-phase staggering operation to maintain costeffective performance. A lower output filter inductance and a higher switching frequency may result in a relatively large ripple current of high frequency at various locations in the rectifier system bus. This large ripple current gives a rise to many serious problems such as heating of the bus and nearby structures, audible noise, electromagnetic interference of the process instrumentations, greater electromagnetic field occupational exposure, etc [12].

Fig. 4 shows the proposed power conversion configuration for a plasma torch system as a main power supply. The circuit parameters and the operating conditions are given in Table I. The proposed power converter topology is designed to meet these operational requirements. A 12-pulse input transformer whose respective secondary winding feeds power to a 6-pulse diode rectifier is employed. The $\mathrm{dc} / \mathrm{dc}$ conversion part consists of two 3-level buck converters connected in series at the output. According to the system input conditions specified in Table I, a dc link voltage of $2.5 \mathrm{kV}$ is supplied. A turn-off device of an IGCT (Integrated Gate Commutated Thyristor) is selected and integrated into this 3-level buck converter [20], [21]. The IGCT is the optimum combination of lowloss thyristor technology and a snubberless, cost-effective gate turn-off [3]. This device has a relatively low loss and a high surge capability in medium voltage applications. Thanks to its thyristor design inheritance and its low inductive gate turnoff, the IGCT has the necessary properties for switching large amounts of electric power in one component. Each of the 3level buck converters shown in Fig. 4 has its own isolated dc link input provided by an isolated secondary winding of
TABLE I

CIRCUIT PARAMETERS AND OPERATING CONDITIONS

\begin{tabular}{l|c}
\hline \multicolumn{1}{c|}{ Parameters } & Values \\
\hline Medium voltage ac input (Vsab) & $22 \mathrm{KV}$ \\
\hline Rectifier input voltage (Vsab_sec) & $1930 \mathrm{~V}$ \\
\hline IGCT switching frequency (Fsw) & $300 \mathrm{~Hz}$ \\
\hline AC line inductance (Lscc) & $12 \mathrm{mH}(2.4 \%)$ \\
\hline Transformers leakage inductance (Llkg) & $472 \mathrm{uH}(6 \%)$ \\
\hline DC link voltage (VdcLink) & $2500 \mathrm{~V}$ \\
\hline DC load voltage (VdcOUT) & $1500 \mathrm{~V}$ \\
\hline DC load currnet (ILoad) & $2000 \mathrm{~A}$ \\
\hline Current control loop p-gain (Kpi) & 0.18 \\
\hline Current control loop i-gain (Kii) & 37.5 \\
\hline
\end{tabular}

the input transformer. The intrinsic characteristics of the 3level voltage source structure and the series connection of two isolated dc link systems makes it possible to supply double the high output de voltage to the load which is a very useful feature during the arc ignition phase. Owing to the two isolated dc link voltages, two 3-level buck converters can be phasestaggered on the output side. This phase-staggering can double the effective switching frequency seen by an output chokeinductor.

This leads to a smaller inductor size and fast current regulation dynamics for the converter. This fast current regulation feature is essential for the arc stability of a plasma torch system.

\section{IgNition Circuitry for Plasma TORChES}

Arcs are difficult to start because they require a power supply with a high voltage to ignite the arc and a large current at a low voltage to maintain the plasma arc in the steady state. Plasma torches requires a relatively high ignition voltage during the arc ignition phase compared to the steady-state condition. In general, this high ignition voltage is provided by an auxiliary high-voltage low-current ignition circuitry. The most common way to generate the gaseous breakdown is by using high voltage impulses at a very high frequency. The conventional method for striking an arc is using a spark gap. A spark gap consists of two conductors and one overstressed dielectric. Normally, the spark gap frequency has a high level of interference which is injected into the main power supply because of abrupt variations in the load current. This may disturb the performance of the control systems and other peripheral devices [7]. In addition, the spark gap limits the life cycle of the ignition circuitry and restults in a need for regular maintenance of the system. As illustrated in Fig. 5, the half bridge series resonant converter is proposed as an auxiliary ignition circuitry to overcome the limitations of a spark gap starter [7], [8]. The circuit parameters are summarized in Table II. This circuit provides the breakdown voltage needed to create arc ignition. Once the ionization channel is generated, a low impedance path is created through the electrodes, and the half bridge series resonant converter delivers current until the gap impedance is low enough to permit the entrance of the main power supply which delivers enough energy to sustain the plasma. Once the arc is established, the surging arc current should be limited to within a safe operating area of the converter system by a current regulation control. By controlling the switching frequency of the converter with 


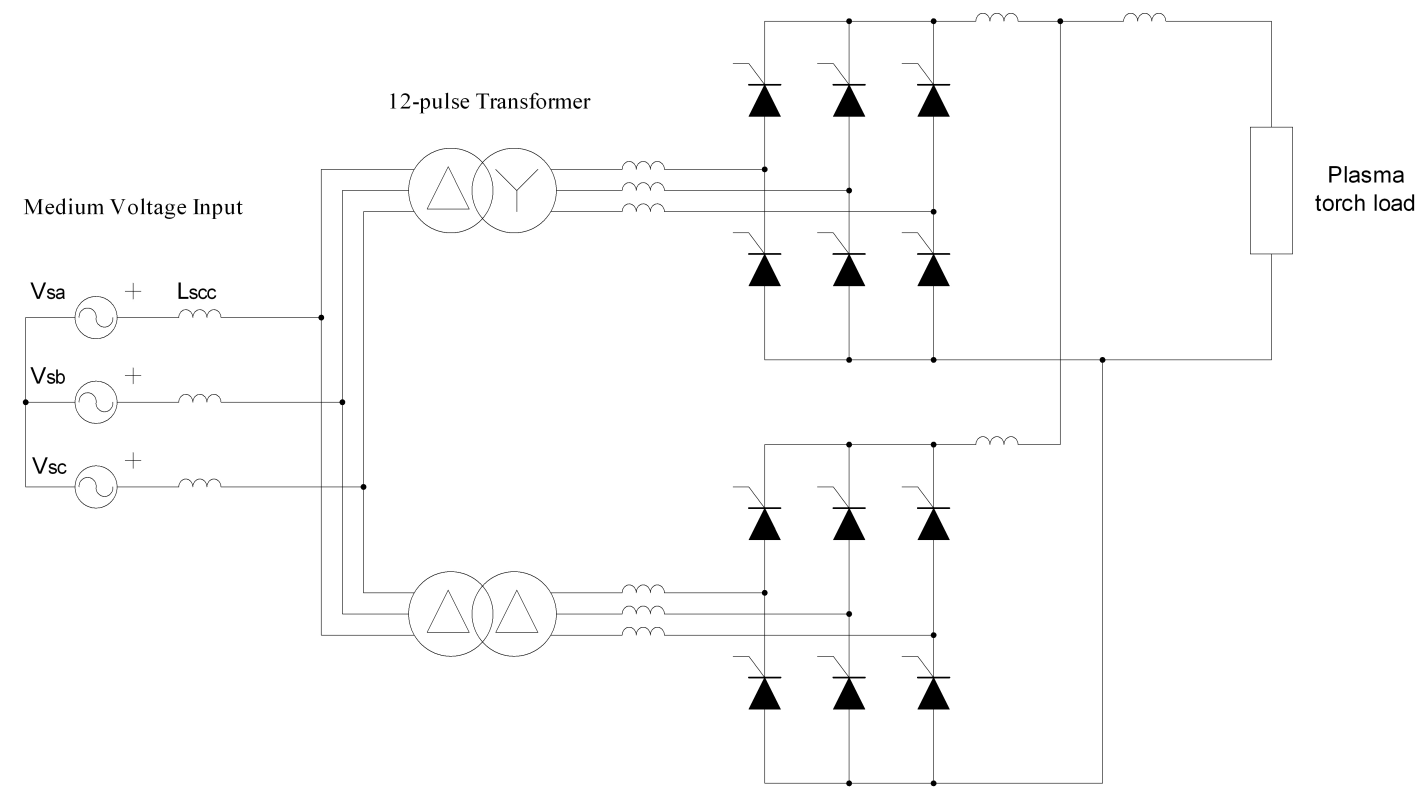

Fig. 2. 12-pulse thyristor rectifier applied for plasma torch system.

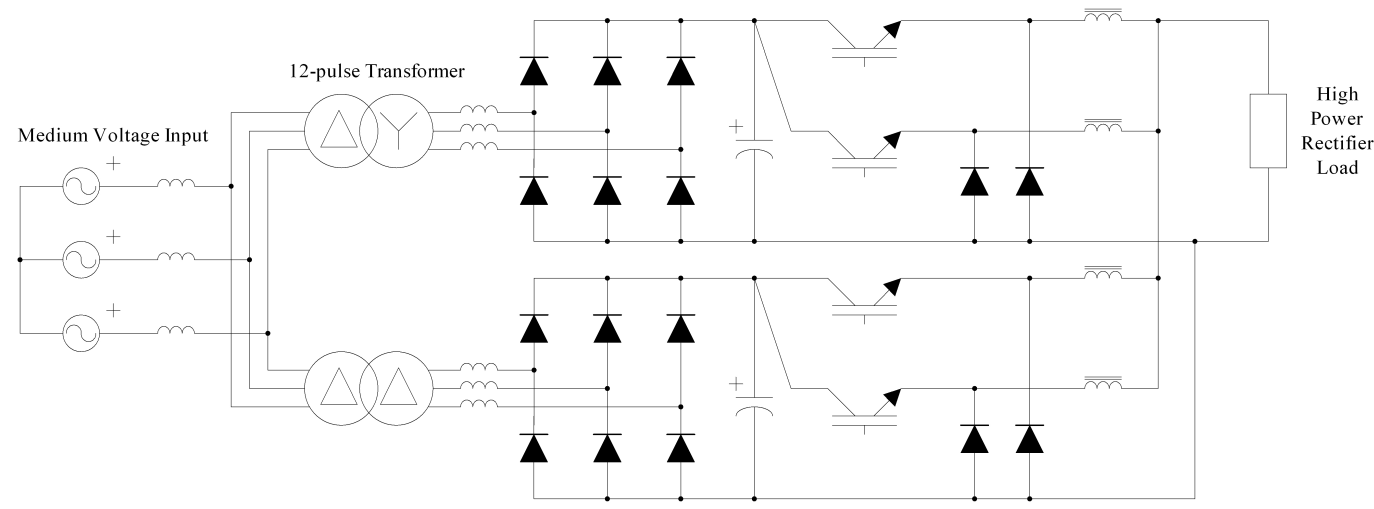

Fig. 3. Chopper rectifier system based on IGBT technology.

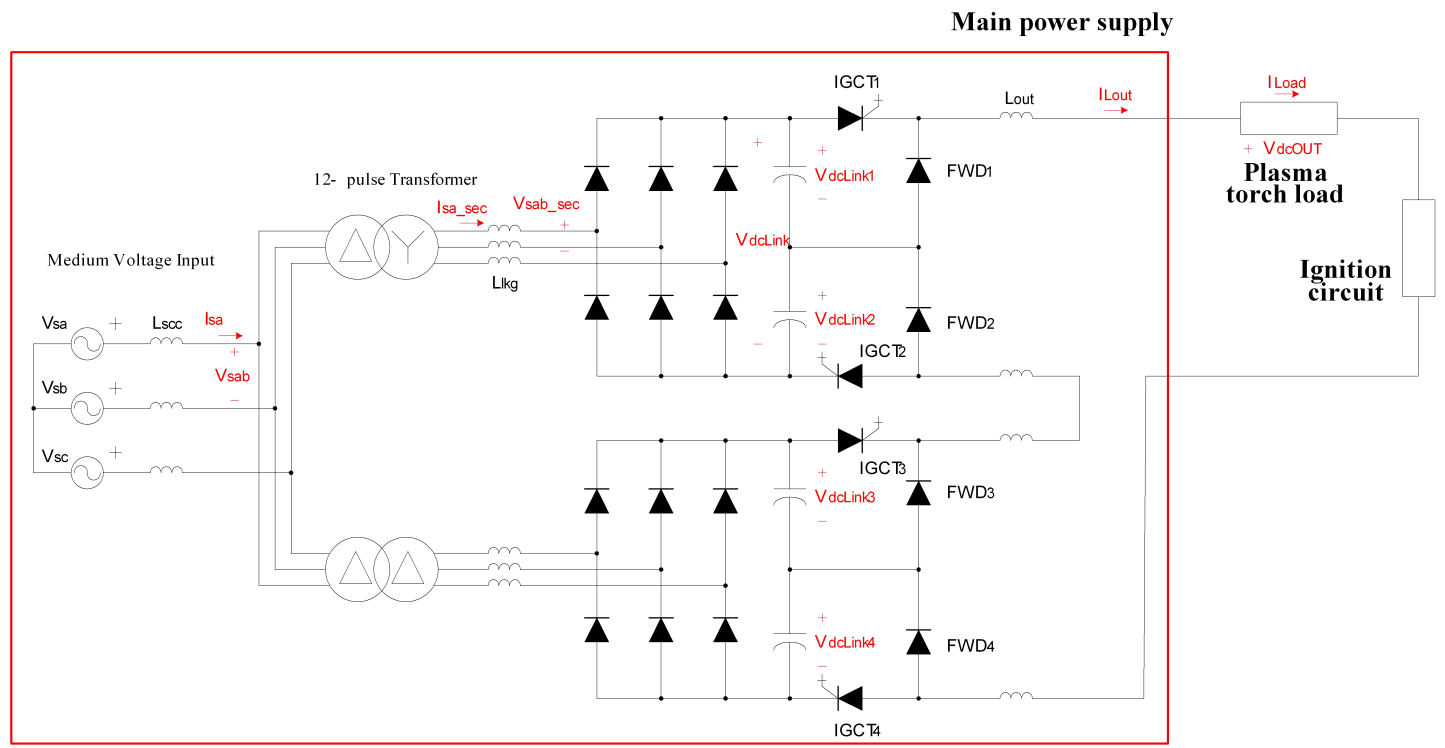

Fig. 4. Proposed power converter configuration for plasma torch system as a main power supply. 


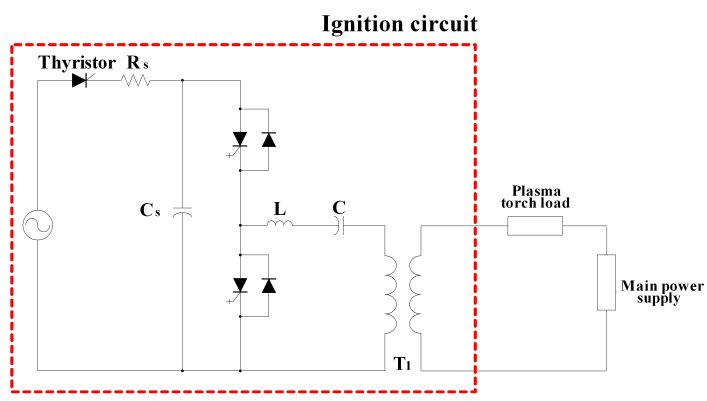

Fig. 5. Employed ignition circuit configuration of half bridge series resonant converter.

TABLE II

CIRCUIT PARAMETERS FOR IGNITION CIRCUIT

\begin{tabular}{l|c}
\hline \multicolumn{1}{c|}{ Parameters } & Values \\
\hline Resonant tank inductance (Lres) & $3.14 \mathrm{mH}$ \\
\hline Resonant tank capacitance (Cres) & $0.08 \mu \mathrm{F}$ \\
\hline IGCT switching frequency (Fsw) & $10 \mathrm{kHz}$ \\
\hline Transformer turn ratio (T) & $1: 20$ \\
\hline Ignition voltage (VIgnition) & $30 \mathrm{kV}$ \\
\hline
\end{tabular}

respect to the resonance frequency, the arc current limitation can be effectively obtained. In addition, owing to the nature of resonance operation, the transition from an open circuit to discharge is not abrupt, but very soft. The operational phase transition from ignition discharge to the steady state is achieved in an effective manner due to the series connection of the secondary side of the ignition transformer and the main power supply. The secondary side of the high voltage transformer which generates a high ignition voltage during the ignition phase becomes short circuited during the steady state providing a short path between the plasma torch and the main power supply.

\section{Operating Characteristics OF Plasma TORCHES WITH A DYNAMIC ARC MODEL}

The arc as a circuit element can be modeled by the dynamic resistance $R_{a}$ which satisfies the Cassie-Mayr equation:

$$
\frac{d R_{a}}{d t}=\frac{R_{a}}{\tau}\left(1-\frac{I_{a} U_{a}}{P}\right)
$$

where $I_{a}$ is the current applied to the arc and $U_{a}$ is the arc voltage. The Greek letter $\tau$ is the time constant of the arc which accounts for the time delay in the arc dynamics. The Prepresents the power loss of the arc due to radiative and convective heat transfers [17], [18]. Both $\tau$ and $P$ depend on the arc current and the arc voltage. In this paper, the arc power loss $\mathrm{P}$ is modeled as follows:

$$
P=P_{0}\left(R_{a} / \hat{R}\right)^{-\alpha}
$$

where $\hat{R}=1.0 \Omega$ is the unit resistance. $P_{0}$ and $\alpha$ are functions of the arc current $I_{a}$ and the arc voltage $U_{a}$. The arc parameters have been calculated by a number of steady and transient arc simulations [5], [6], [19]. The arc model described in Eq. (1) and (2) has been integrated into the circuit simulation tools of Matlab Simulink and Plecs. This is to simulate the arc characteristics of the plasma torch within the scope of a complete power conversion system under the conditions of the arc ignition phase as well as steady-state operation. An arc voltage noise disturbance of $\pm 10 \%$ in amplitude and $900 \mathrm{~Hz}$ in frequency, caused by an internal periodic pressure wave inside the plasma torch, is modeled and applied to the dynamic arc load during steady-state operation.

Fig. 6, 7 and 8 illustrate the simulated weakly blown electric arc inside the plasma torch. Fig. 6 shows the simulated equalcurrent-density surface which confines the arcing zone. Figure 7 shows the velocity profile on a vertical plane-cut. The high velocity region along the vertical axis corresponds to the high temperature $(\mathrm{T}>7000 \mathrm{~K})$ arcing region where the air density is low. The arcing zone shows the high velocities caused by a low gas density for a given mass flux rate. Selected streamlines from the flow inlet to the outlet are also shown. From the transient arc simulation, it is important to note the periodic arc voltage noise generation due to hydrodynamic disturbances. A snap shot of the pressure distribution inside the plasma torch is shown in Fig. 8. Note that there is a high pressure region formed in the anode cap. This is due to the fact that the radiative arc energy is pumped into and trapped in the anode cap. Consequently, the heat energy is converted into hydraulic pressure there. The high pressure region periodically relaxes once the pressure reaches a critical value, which generates a periodic pressure wave. The disturbance in the arc profile changes the conductivity of the arcing column, which results in periodic arc voltage fluctuations. Figure 9 shows the arc voltage fluctuation curve obtained from the transient $3 \mathrm{D}$ arc simulation under an arc current of $2 \mathrm{kA}$. It is noted from Fig. 9 that the arc voltage follows a sawtooth waveform pattern fluctuating around $1500 \mathrm{~V}$, which corresponds to the arc parameter setting given by $P_{0}=2.625 \times 10^{6}$ and alpha $=1.0$. The average frequency of the arc voltage fluctuation is approximately $900 \mathrm{~Hz}$ with an average amplitude equal to $300 \mathrm{~V}$. This amplitude corresponds to a $P_{0}$ fluctuation amplitude of $40 \%$. This pressure wave disturbance has a detrimental effect on the arc stability and on the stable operation of the overall power conversion system unless proper countermeasures are taken. The simulation results on the operation of a 3-level dc-dc converter is illustrated in Fig. 10. The turn on duty of each IGCT is controlled to regulate the output load current to the given reference value. The turn-on instant of IGCT2 is delayed by 180 degree of a switching period from the turnon instant of IGCT1. Therefore, the turn-on pulses of IGCT2 are phase-staggered between those of IGCT1 as shown in Fig. 10. The lower block of a 3-level dc-dc converter that is fed by the delta connected secondary winding of a transformer has the same phase staggering operation between IGCT3 and IGCT4. Two blocks of 3-level dc-dc converters have a phase shift of 90 degree of a switching period from each other. That means the turn-on of IGCT3 is delayed by 90 degree from that of IGCT1. This is made possible by the isolated supply of two secondary windings and the decoupling output inductors. As a result, the output inductor current (ILout) a switching frequency that is four times more effective when compared to the given switching frequency of each IGCT.

This makes the size of the output inductor small and it also provides a faster regulation control of the output load current. The simulation waveforms on the load side are illustrated in Fig. 10 and 11. In Fig. 11, the dc arc current, the dc 


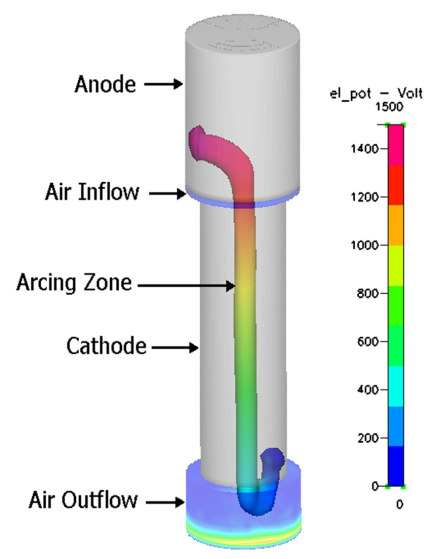

Fig. 6. Equal-current-density surface $\left(j_{t o t}=5.0 \cdot 10^{5} \mathrm{~A} / \mathrm{m}^{2}\right)$ confining arcing zone in plasma torch.

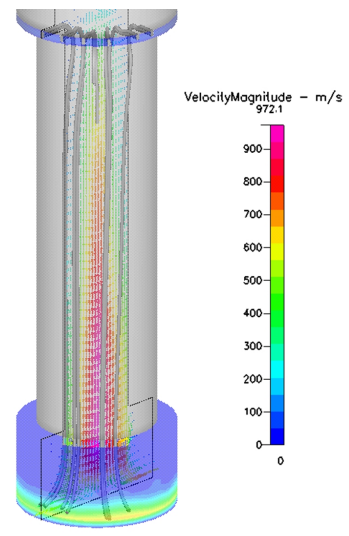

Fig. 7. Velocity distribution at a vertical cut of plasma torch.

arc voltage, and the dynamic arc resistance are shown. In general, plasma torches have a negative dynamic resistance characteristic which is an intrinsic property of discharging arc loads.

This is visible from the waveform of the arc resistance (Rarc) in Fig. 11. Upon a sharp decrease in arc voltage due to a load disturbance, the arc current is increased rather than decreased resulting in a negative incremental slope of the resistance. It is this negative incremental slope of resistance which makes the plasma arc system unstable unless proper control measures are taken. The proposed converter solution can stabilize such instabilities through a fast regulation of the output current with a small sized output inductor. Fig. 12 shows the same arc current and its frequency spectrum. It is noted from these two figures that the peak-to-peak ripple of the arc current is maintained within $\pm 8.8 \%$ of its rated value of $350 \mathrm{~A}$. The major harmonic is at $1.2 \mathrm{kHz}$ and this is due to four times the switching frequency $(300 \mathrm{~Hz})$ of each IGCT. The harmonic spectrum well describes the influence of the arc voltage noise disturbance of $900 \mathrm{~Hz}$. It creates $300 \mathrm{~Hz}$ and multiples of the $900 \mathrm{~Hz}$ harmonics. This is due to the interference between the carrier frequency of $1.2 \mathrm{kHz}$ and the arc disturbance of $900 \mathrm{~Hz}$. One of many important operational requirements of a power supply system for a plasma torch is the capability of fast current regulation under various unstable arcing conditions, i.e. initial arc ignition, load disturbances, internal pressure

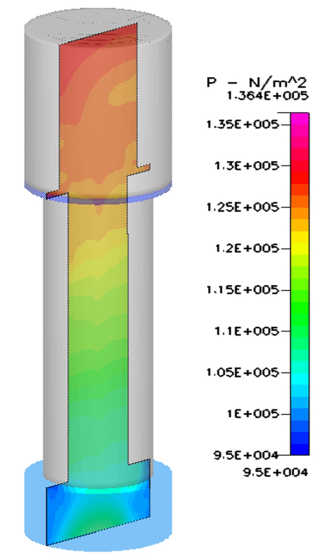

Fig. 8. Pressure distribution at a vertical cut.

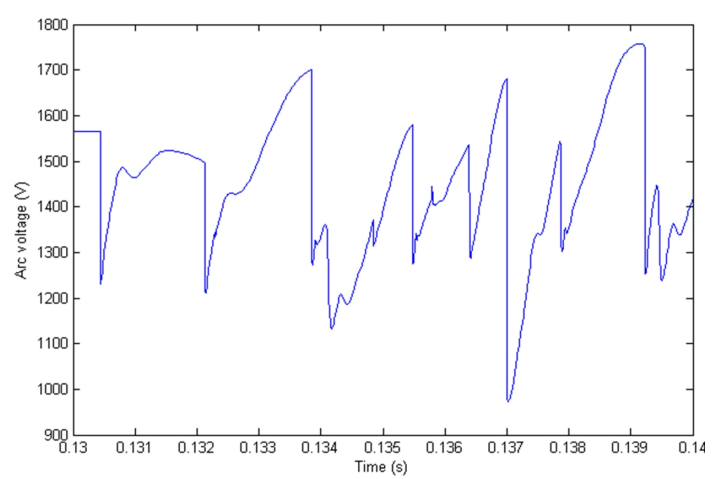

Fig. 9. Arc voltage fluctuation waveform due to periodic pressure wave inside torch obtained through transient 3D arc simulation.

wave disturbances, etc. The step load disturbance of the arc voltage on top of the internal pressure wave disturbance is applied to the power supply system to implement a realistic dynamic operating condition. The dynamic behaviour of the power supply system, particularly with the regulation of output load current, is investigated. The related simulation results are provided in Fig. 13. This figure explains the dynamic response characteristics of the proposed converter system upon the step load response at the instants of 0.2 and $0.3 \mathrm{~s}$. The resulting output load current is shown at the bottom of Fig. 13. This confirms the effectiveness of the proposed converter system under dynamic operating conditions. Figure 14 illustrates the operating characteristics of the proposed half bridge resonant ignition circuitry. This figure shows the pole voltage, the resonant current and the ignition voltage. A power supply system similar to the one described in Fig. 4 has been built and tested to confirm the feasibility of the proposed solution. The power stack, namely a PEBB (Power Electronics Building Block), equipped with all of the semiconductors from the front-end rectifier and the 3-level step-down $\mathrm{dc} / \mathrm{dc}$ converter is shown in Fig. 15.

An IGCT rated 4kA/4.5kV (5SHY 35L4510, ABB Semiconductor) is used in the stack due to the optimized conduction and switching loss characteristics [14]. The press pack mounting technology, using the mechanical structure of the stack, provides very efficient cooling and electrical contacts to the semiconductors when compared to IGBT module technology. 


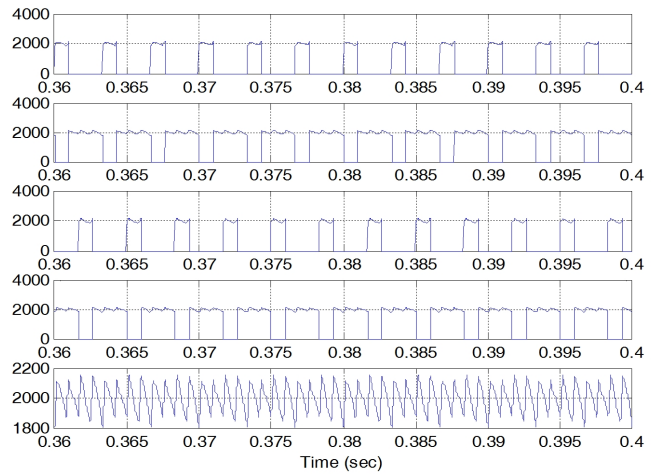

Fig. 10. Simulation waveforms at 3-level dc/dc converter part (From the top: IIGCT1, IFWD1, IIGCT2, IFWD2, and ILout).
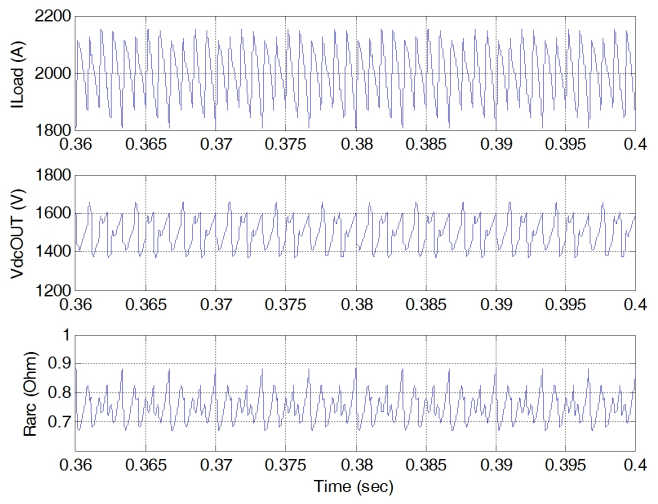

Fig. 11. Simulation waveforms at the dynamic load of plasma torch (From the top: ILoad, VdcOUT, and Rarc).

As a result, a high power density and reliable short-circuit performance can be achieved through the power stack technology. The waveform in Fig. 16 describes the switching behavior of the IGCT at the point of 5.2kA in the employed power stack. It shows the turn-off time, the switching trajectory of voltage/current, and the switching loss. It is noted that the IGCT current of $5.2 \mathrm{kA}$ is successfully commutated to the fast diode within 2 us. This confirms the high current switching capability of the IGCT in this high power rectifier application. Additional experimental verification is planned and the corresponding results will be reported in future publications.

\section{Conclusions}

This paper proposes a power supply of medium voltage with enhanced ignition characteristics for plasma torches. The series resonant half-bridge topology is presented as a suitable ignition circuitry. The ignition circuitry is integrated into the main power conversion system. A plasma torch rated for $3 \mathrm{MW}$, $2 \mathrm{kA}$ and having a physical size of $1 \mathrm{~m}$ is selected to be a high enthalpy source. The dynamic characteristics of the DC arc in the plasma torch are investigated using advanced 3D magneto-hydrodynamics simulations. These simulations show the existence of an arc disturbance noise of $900 \mathrm{~Hz}$ due to the periodic pressure wave inside the plasma torch during steadystate operation. This arc noise can give a rise to arc instability unless properly compensated by a current control scheme. Simulation waveforms confirm that the proposed power converter system has superior dynamic performance under the existence of load disturbances. The proposed power conversion
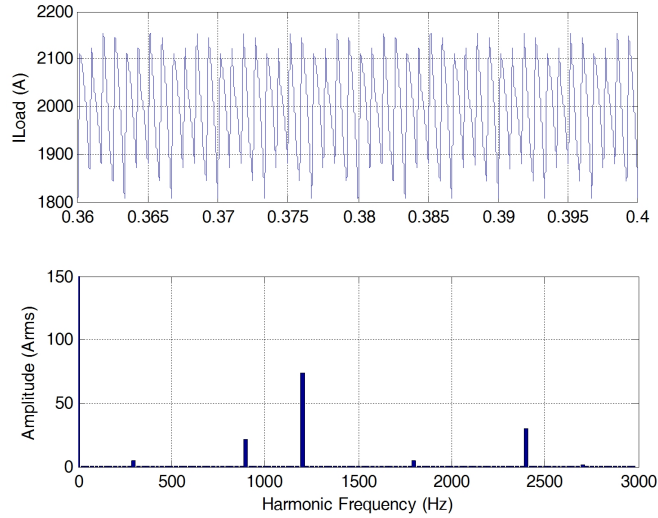

Fig. 12. Frequency spectrum of dc arc current in the dynamic load (From the top: ILoad and frequency spectrum).
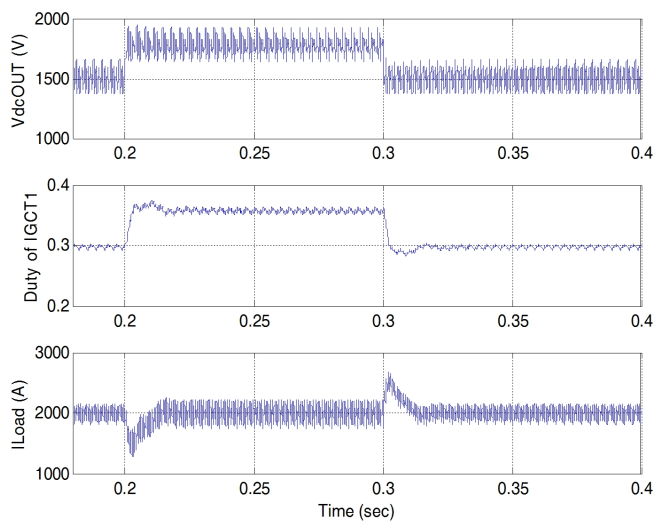

Fig. 13. Transient response to step arc voltage change due to arc instability in the plasma system (From the top: VdcOUT, turn-on duty ratio of IGCT1, and ILoad).
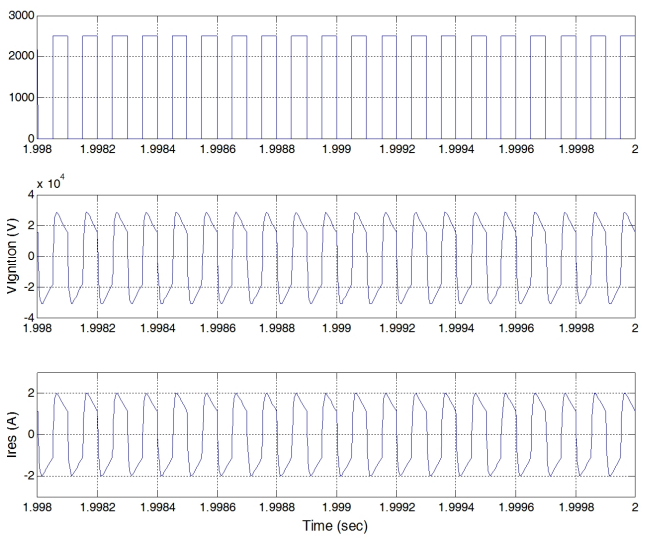

Fig. 14. Simulation waveforms in ignition circuitry part (From the top: Vp_res, Ires, and VIgnition). 


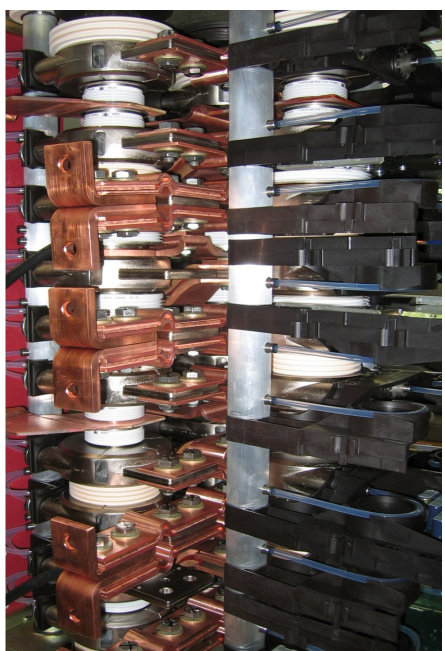

Fig. 15. Photograph of 5kA proto-type IGCT power stack (Dimension: $1 \mathrm{~m} \times$ $0.5 \mathrm{~m} \times 0.8 \mathrm{~m})$.

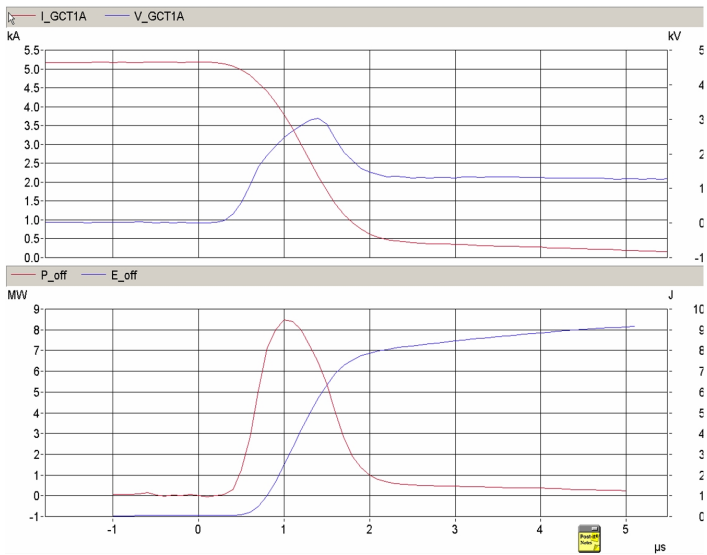

Fig. 16. Experimental waveforms of IGCT switching-off at 5.2kA (From the top: switching current, voltage, power, and energy).

configuration, including the ignition circuitry, provides a high enough ignition voltage, around $5 \mathrm{kV}$, during the ignition phase and high arc stability under the existence of intrinsic arc disturbance noise resulting in a high-performance plasma torch system.

\section{ACKNOWLEDGMENT}

This work was supported by the National Research Foundation of Korea (NRF) grant funded by the Korean government (MEST) (No. 2010-0029429).

\section{REFERENCES}

[1] S. L. Camacho, "Industrial-worthy plasma torches: State of the art," Pure Appl. Chem., Vol. 60, No. 5, pp. 619-632, 1988.

[2] M. Hur, K. D. Kang, and S. H. Hong, "Numerical analysis on plasma characteristics of high power plasma torch of hollow electrode type for Waste treatment," in Proc. IEEE Rec. Int. Conf. Plasma Sci., p. 285, May 1997.

[3] T. Iwao, M. Yumoto, H. Nishiwaki, and T. Inaba, "Development of 300 $\mathrm{kW}$ twin torch plasma arc furnace for medical waste treatment," in Proc. IEEE Rec. Int. Conf. Plasma Sci., p. 84, 2006.

[4] P. Fauchais and A. Vardelle, "Thermal plasmas," IEEE Trans. Plasma Sci., Vol. 25, pp. 1262-1267, Dec. 1997.

[5] Y. Suh, Y. Lee, J. Kheir, and P. Steimer, "A study on medium voltage power conversion system for plasma torch," in Proc. IEEE Power Electron. Spec. Conf., pp. 437-443, 2008.
[6] Y. S. Suh, Y. Lee, and P. Steimer, "A comparative study of medium voltage power converter topologies for plasma torch under dynamic operating conditions," IEEE Trans. Ind. Electron., Vol. 56, No. 6, pp. 2150-2161, Jun. 2009.

[7] J. Pacheco-Sotelo, R. Pena-Eguiluz, L. P. Eguiluz, A. S. de los Rios, and G. C. Sanchez, "Plasma torch ignition by a half bridge resonant converter," IEEE Trans. Plasma science, Vol. 27, No. 4, pp. 1124-1130, Aug. 1999.

[8] S. D. Roos, J. A. Ferreira, and W. G. Odendaal, "A plasma torch converter based on the partial series resonant converter," IEEE Power Electron. Spec. Conf., Vol. 2, pp. 1388-1394, Jun. 1997.

[9] T. Siebert, A. Troedson, and S. Ebner, "AC to DC power conversion now and in the future," in Proc. IEEE Ind. Appl. Soc. Petroleum Chem. Ind.Conf., pp. 145-152, 2001.

[10] V. Scaini and T. Ma, "High-current dc choppers in the metals industry," IEEE Ind. Appl. Mag., Vol. 8, No. 2, pp. 26-33, Mar./Apr. 2002.

[11] P. S. Maniscalco, V. Scaini, and W. E. Veerkamp, "Specifying DC chopper systems for electrochemical applications," IEEE Trans. Ind. Appl., Vol. 37, No. 3, pp. 941-948, May/Jun. 2001.

[12] M. Mazaheri, V. Scaini, and W. E. Veerkamp, "Cause, effects and mitigation of ripple from rectifiers," IEEE Industry Applications Society Petroleum and Chemical Industry Conference, pp. 85-91, 2002.

[13] P. Ladoux, G. Postiglione, H. Foch, and J. Nuns, "A comparative study of AC/DC converters for high-power dc arc furnace," IEEE Trans. Ind. Electron., Vol. 52, No. 3, pp. 747-757, Jun. 2005.

[14] Y. S. Suh and P. Steimer, "Application of IGCT in high power rectifiers," IEEE Trans. Industry Applications, Vol. 45, No. 5, pp. 1628-1636, Sep./Oct. 2009

[15] J. R. Rodriguez, J. Pontt, C. Silva, E. P. Wiechmann, P. W. Hammond, F. W. Santucci, R. Alvarez, R. Musalem, S. Kouro, and P. Lezana, "Large current rectifiers: State of the art and future trends," IEEE Trans. Ind. Electron., Vol. 52, No. 3, pp. 738-746, Jun. 2005.

[16] S. M. Hwang, Y. S. Kim, and C. J. Doh, "Cyclonic plasma pyrolysis system," World Intellectual Property Organization Patent, WO2005/106327 A1, 10 Nov. 2005.

[17] A. M. Cassie, "Arc rupture and circuit severity," International des grands reseaux electriques a haute tension CIGRE, Paris, France, Report 102, 1939.

[18] K.-J. Tseng, Y. Wang, and D. M. Vilathgamuwa, "An experimentally verified hybrid Cassie-Mayr electric arc model for power electronics," IEEE Trans. Power Electron., Vol. 12, No. 3, pp. 429-436, May 1997.

[19] Y. J. Lee, Y. Suh, H. Nordborg, and P. Steimer, "Arc stability criteria in AC arc furnace and optimal converter topologies," in Proc. APEC, pp. 1280-1286, 2007.

[20] P. K. Steimer, H. E. Gruening, J. Werninger, E. Carroll, S. Klaka, and S Linder, "IGCT-A new emerging technology for high power, low cost inverters," IEEE Ind. Appl. Mag., Vol. 5, No. 4, pp. 12-18, Jul./Aug. 1999.

[21] P. K. Steimer, B. Oedegard, O. Apeldoorn, S. Bernet, and T. Brueckner, "Very high power IGCT PEBB technology," in Proc. PESC, pp. 1-7, 2005.

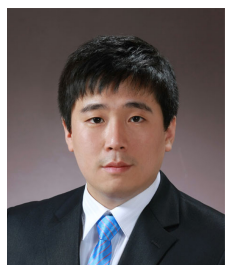

Kyungsub Jung was born in the Republic of Korea in 1982. He received his B.S. in Electrical Engineering from Chonbuk National University, in 2008, and is currently pursuing his M.S. at Chonbuk National University. His research interests include power conversion systems of high power for renewable energy sources and medium electric drive systems.

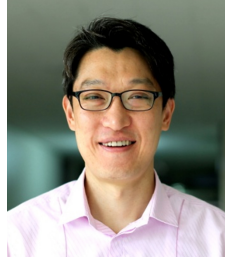

Yongsug Suh (M'90/SM'07) was born in Seoul, Korea $\mathrm{He}$ received his B.E.E. and M.S.E.E. from Yonsei University, Seoul, Korea, in 1991 and 1993, respectively, and his $\mathrm{Ph} . \mathrm{D}$. in Electrical Engineering from the University of Wisconsin, Madison, in 2004. From 1993 to 1998, he was an Application Engineer in the Power Semiconductor Division of Samsung Electronics Co. From 2004 to 2008, he was a Senior Engineer in the Power Electronics \& Medium Voltage Drives Division of ABB, Turgi, Switzerland. Since 2008, he has been with the Department of Electrical Engineering, Chonbuk National University, Jeonju, Korea, where he is currently an Assistant Professor. His research interests include power conversion systems of high power for renewable energy sources and medium voltage electric drive systems. 